\title{
CPTED and Workplace Violence in Jordanian Public Hospitals
}

\author{
Afnan Sharif Saleh ${ }^{1}$, Naser Ibrahim Saif ${ }^{2} \&$ Khaled Sufian Sartawi ${ }^{3}$ \\ ${ }^{1}$ Department of Architecture Engineering, Philadelphia University, Amman, Jordan \\ ${ }^{2}$ Department of Hospital Management, Philadelphia University, Amman, Jordan \\ ${ }^{3}$ School of Business and Quality Management, Hamdan Bin Mohammed Smart University, Dubai \\ Correspondence: Naser Ibrahim Saif, Department of Hospital Management, Philadelphia University, Amman, \\ Jordan. Tel: 96-27-9994-2042. E-mail: naser.saif@ymail.com
}

\author{
Received: October 28, 2014 Accepted: December 17, 2014 Online Published: January 14, 2015 \\ doi:10.5539/ass.v11n4p336 URL: http://dx.doi.org/10.5539/ass.v11n4p336
}

\begin{abstract}
In recent years, workplace violence (WPV) has become a serious problem in public hospitals in Jordan. This study focuses on whether and how the use of architectural and management solutions that rely mainly on the Crime Prevention through Environmental Design (CPTED) approach (including natural surveillance, natural access control, territorial concern, and management \& maintenance) has worked for two Jordanian public hospitals in controlling WPV. This study employed a descriptive research design, and data were collected using quantitative and qualitative methods. The sample population included all the workers at two major referral public hospitals in Jordan. This study found that the hospitals attempted to make significant use of CPTED but that CPTED usage was at least partially ineffective because of poor implementation of its principles and because employees were not sufficiently educated in CPTED to exploit the CPTED engineering and design features. Thus, certain factors that might induce violence were not effectively addressed at both of the hospitals studied. This study thus provides a clear picture of a number of issues contributing to WPV in Jordanian public hospitals that must be addressed by those in charge.
\end{abstract}

Keywords: workplace violence, CPTED components, public hospital, Jordan

\section{Introduction}

Somewhat counter intuitively, health care is a dangerous occupation (Taylor \& Rew, 2010), and one aspect of this danger involves workplace violence (WPV). Healthcare providers are at greater risk for violence than workers in many other fields (Elliott, 1997; Zun, 2013). Specifically, WPV in public hospitals is a significant and serious worldwide problem (Gagne, 2014) that affects both developed and developing countries (Bowie, Fisher, \& Cooper, 2012) and occupational health, in particular (Newman, Vries, Kanakuze, \& Ngendahimana, 2011). WPV prevention can only be managed under thoughtfully packaged actions that implement more than one strategy to avert violence (Kerr, 2010). Thus, many parties have implemented actions based on different strategies to resolve the WPV problem. These intervention strategies include management and engineering actions (World Health Organization, 2002), and the most well-known of the engineering implementations involve architecture.

Architects address many critical issues in today's society. Architecture considers that edifices are built for people; all safe buildings must meet particular functional criteria. Moreover, architecture has a significant impact in controlling WPV (Charney, 2010). An important approach to architectural and management solutions to prevent WPV is the approach known as Crime Prevention through Environmental Design (CPTED) (Duarte, Lulham, \& Kaldor, 2011; The Japan Institute for Labour Policy and Training, 2013). CPTED involves a set of principles that can be applied to design and that play an important role in promoting and reducing crime and violence (Hopper, 2013; Cullen \& Wilcox, 2010). In brief, the CPTED approach proposes that proper design standards and use of the built environment and operational organization can help reduce the risk of violence and the actual incidence of violent activity (Parnaby, 2006). Previous studies involving large-scale assessments of WPV prevention programs based on CPTED principles have found that service organizations that applied CPTED principles experienced significant decreases in WPV (Kelloway \& Cooper, 2011; Fennelly, 2012).

WPV is a widespread phenomenon and major problem in Jordanian public hospitals (Jordanian Minister of Health, 2014) that requires an urgent solution (Al-Nsour \& Khawaja, 2009). Further, there is limited information 
about the basis of intervening actions that attempt to prevent WPV events and their complications (Saleh \& Saif, 2014). An improved understanding regarding the use of architecture and management solutions may thus lead to better control of WPV. This study aims to explore whether and how Jordanian public hospitals might benefit from architectural and management solutions based on the CPTED approach that have been shown to mitigate violence.

\section{Study Objective}

This study seeks to answer the following research question that has arisen from the absence of relevant studies that address controlling WPV through architectural and management solutions: How can the use of CPTED-based solutions help prevent WPH in Jordanian public hospitals?

\section{Literature Review}

\subsection{Workplace Violence}

The European Commission has defined WPV as "incidents where persons are abused, threatened or assaulted in circumstances related to their work, involving an explicit or implicit challenge to their safety, well-being or health" (Paludi, Nydegger, \& Paludi, 2006). WPV is a community problem that has attracted increasing attention (Hacioglu \& Dinçer, 2014; Kelly \& Portes, 2013); it arises in many forms and settings and affects many people in their work (Hamby \& Grych, 2012), including workers in the healthcare sector (Mayhew \& Chappell, 2003). Thus, WPV is a threat to productivity and quality of work, and researchers have analogized hospital work to working on the front lines of a war zone (Lyneham, 2000; Patrick, 2013). Moreover, healthcare organizations struggle to combat WPV (Duffy, 2013)-which can take many forms in healthcare organizations-and these organizations must thus be ready to address the problem in different permutations (Pyrek, 2011). The effects of WPV are serious and expensive and can range from minor to major physical injuries, temporary or permanent physical disability, psychological trauma and even death (Philpott \& Grimme, 2009). The financial costs of WPV are estimated in the billions of dollars annually; these costs arise directly from security, medical and legal expenses, lost time at work and other financial losses (Taylor \& Rew, 2010). WPV prevention-in addition to readiness and response arrangements-should be recognized and maintained by all healthcare organizations (International Labour Office, 2003). The World Health Organization and many social service agencies recommend establishing management and engineering protocols as part of public and private healthcare organizations' comprehensive programs for controlling and preventing WPV (Charney, 2010).

\subsection{Crime Prevention through Environmental Design}

CPTED is a multidisciplinary process developed to control crime, violent behavior and inappropriate activity through environmental design (British Columbia Housing Matters, 2014). CPTED is based on four key principles of natural surveillance, access control, territorial reinforcement and management \& maintenance; these principles are built on the proposition that crimes against people and property are minimized when other people are around, if people in contiguous areas and spaces are able to see what is occurring and if people are given safe choices about where to be and how to respond to problems.

A review of the hospital design literature demonstrates that hospital design has an impact on WPV and also indicates the directions in which organization management can take a more active role in architectural design (Cozens, Saville, \& Hillier, 2005; Doll, Bonzo, Mercy, \& Sleet, 2007; Wassell, 2009; Holmes, Perron, \& Rudge, 2013). An effectively designed environment makes people feel safer and minimizes the chances for criminal and violent acts to occur. CPTED is an approach to problem solving that analyzes and utilizes environmental conditions and the operational opportunities they offer for crime, violence or other unintended and undesirable behaviors (Zahm, 2007). CPTED principles and strategies are used to identify and combine design features that reduce the opportunities for violence. WPV prevention through environmental design derives from diverse disciplines concerned with the interactions between people and the physical environment (Schneider \& Kitchen, 2007). CPTED was first developed by the criminologist C. Ray Jeffery and the architect Oscar Newman (Silverstein, 2011). Newman's 1972 book (Newman, 1972), "Defensible Space, Crime Prevention through Urban Design", set forth rules that were broadly adopted with varying degrees of success. By 2004, elements of the CPTED approach had acquired broad international approval due to law enforcement efforts to transform CPTED into a multi-disciplinary approach to crime and violence prevention (Saville \& Cleveland, 2008).

CPTED is the most well-known design-based crime and violence control and prevention theory; it supplies a procedure for a set of design approaches that can be made to suit a particular site or activity based on that space's specific requirements and problems. CPTED provides a rich boundary of striated space and redesigns the usage of space to incorporate barriers, to schedule space, to increase natural surveillance, to place safe activities in safe 
locations (Crowe \& Zahm, 1994), and to overcome distance by communication (Wortley \& Mazerolle, 2011). CPTED cannot stop violence, but it can reduce the opportunities for violence in the built environment, which thus influences the extent to which violent acts are likely to occur. CPTED seeks to control violence by using natural surveillance, natural access control, and territorial reinforcement, in addition to management \& maintenance (Vellani, 2007; Sennewald \& Christman, 2008).

\subsubsection{Natural Surveillance}

Natural surveillance is the concept of positioning "eyes on the location" and creating a location that is unattractive for violent offenders. The essential principle of natural surveillance is that perpetrators of hostile activities seek to remain unobserved. Natural surveillance creates the condition of feeling continually under observation by other residents in the specific areas of a residential environment. Natural surveillance involves the observation of areas by people and thus utilizes design features to increase the visibility of buildings (U.S. Safety and Justice Program, 2009). Thus, natural surveillance requires open areas where users can be observed through a visible connection. Natural surveillance is achieved by augmenting the ability of users to see further more easily and by decreasing the ability of users to hide and engage in inappropriate actions without being observed. Windows, glass walls, positioning of public areas, and lighting can improve natural surveillance (Vellani, 2007).

\subsubsection{Natural Access Control}

Natural access control refers to controlling access to ingress and egress locations at a site (Tipton \& Krause, 2007). Natural access control is the power to command and restrict access to a building by means of enclosures, landscaping, sidewalks, lighting, and walkways. This type of control includes focusing on formal and informal entryways and exits, which is a strategy that is organized, mechanical, and natural. The essential thrust of an access control strategy is to deny access to persons who have violent intentions and to engender a perception of risk in offenders (Fennelly \& Crowe, 2013). Natural access control is not necessarily a means of thrusting violence out of a space, but guarantees that entrances can be observed and that they are well lit and supervised (Nicholas, 2012).

\subsubsection{Territorial Reinforcement}

Territorial reinforcement employs physical barriers to demonstrate property demarcation, such as through the use of fences. The concept of territoriality creates a sense of demarcation in a manner that creates an environment in which the presence of an outsider with inappropriate intentions is more easily identified. The way that spaces are defined can create a welcoming feeling in welcome users or an unwelcoming feel in unwelcomed users. Territorial use can create or extend a sphere of influence (Federal Emergency Management Agency, 2008), and physical design can generate or spread a sphere of influence. In this setting, users develop a sense of territorial control; potential offenders perceive this control and are discouraged from their criminal intentions (Hall \& Giglio, 2010).

\subsubsection{Management \& Maintenance}

Management \& maintenance is a significant aspect of CPTED that allows for the continued use of areas for their intended uses. The "Broken Windows Theory" is the basis of the maintenance principal. It is important to maintain a building and to keep its security components in good working order. Equipment and materials that are used in a dwelling should be designed and/or selected with safety and security in mind (Hall \& Giglio, 2010). Management of properties is essential to ensure that maintenance is kept up to appropriate standards of care (Walsh, 2003). Maintenance must also be fixed at the design stage because the choice of materials and finishes will have an impact on the types of maintenance systems that can be sustained by the property owner.

The main concept behind these components that relates specifically to individual safety is that, wherever possible-and probable-it is important to give persons safety sets and to show them how to anticipate harmful situations and return to safety. CPTED seeks to design and manage built environments by encouraging the lawful use of their public components by many people and to allow people external to those public places see what is occurring therein and in nearby buildings, to avoid "hidden" places, and to encourage those who "see something happening" to draw attention to this activity and act (Queensland Crim Prevention Programs, 2007).

\subsection{Background Hospitals under Study}

This study was implemented in the two main public hospitals in Jordan (A\&B), which are both located in Jordan's capital, Amman; together, these hospitals represent approximately half of the hospital beds owned by the Jordanian Ministry of Health. 
Hospital A is the oldest public hospital in Jordan and was established in 1954. It is a major comprehensive referral hospital with 1,030 beds. Due to its size and important role in providing healthcare services to a large number of citizens, Hospital A has received constant and specialized treatment by the government of Jordan and from international aid and donation programs. One of the main strategic projects for the hospital was to renovate certain of its buildings during the 2003-2010 period (Saif \& Saleh, 2013). Hospital B is the newest public hospital in Jordan; it was established in 2003, and has 450 beds. Hospital B is categorized as a major referral hospital that provides all essential healthcare services (Ministry of Health, 2013).

\section{Study Design}

This exploratory study employed quantitative and qualitative methods, all in accordance with Ministry of Health ethical standards. The quantitative method explores and explains whether and how many people hold a certain opinion (Immy, 2005); it is implemented by surveying a large number of participants. Conversely, qualitative research offers an understanding of the root of problems (Humphrey \& Lee, 2008; Cottrell \& McKenzie, 2011). Cottrell et al. (2011) indicate that qualitative data collection can be incorporated to provide more insight, interpretation and a deeper understanding of quantitative results, in addition to obtaining a more detailed understanding of a study problem.

The quantitative research method was implemented in this study to explore the attitudes of staff toward hospitals using the components of CPTED that are related to controlling WPV. The sample included all staff employed in hospitals $\mathrm{A}$ and $\mathrm{B}$, and these two hospitals represent the major referral public hospitals in Jordan. The questionnaire used to complete the quantitative stage of the study aims to address the following hypotheses:

H1: Jordanian hospitals did not use natural surveillance.

H2: Jordanian hospitals did not use natural access control.

H3: Jordanian hospitals did not use territorial concern.

H4: Jordanian hospitals did not use management \& maintenance.

The questionnaire consisted of two parts with 41 questions: the first section included demographic variables, and the second consisted of 34 statements. The questionnaire was designed based on CPTED characteristics. Once the questions were developed, a five-point Likert scale was applied, with responses ranging from "strongly agree" to "strongly disagree". The questionnaire was administered to 390 employees. A total of 326 questionnaires were returned, yielding a response rate of $83 \%$.

Qualitative data were analyzed using SPSS software. Many statistical techniques were utilized, including descriptive statistics to characterize the sample (frequencies, percentages, means, and standard deviations) and Cronbach's $\alpha$ (alpha) to measure the internal consistency of the questionnaire. The values of the Cronbach's alphas ranged from $\alpha=0.85$ to $\alpha=0.89$ in this study, which is well within the acceptable range (Elizabeth \& Jonathan, 2013). One-sample t-tests were used to analyze the responses to the questionnaire, and the level of significance was set at alpha $(\alpha \leq 0.05)$ level.

The qualitative component consisted of two focus groups (FGs). FGs are suitable and common in research focusing on healthcare providers and offer a quick and efficient method of collecting data, in addition to tending to exhibit strong validity (Reed \& Payton, 1997). FGs can improve the understanding of theory and provide group interaction, discussion direction, and comfortable and in-depth exploration that enhance the detailed exploration of the topic at hand (Wiid \& Diggines, 2009).

FGs are implemented to explore the attitudes of specialists, support personnel and the findings of quantitative surveys. The topics of the FGs that were put forward in this study related to the following question: "How do Jordanian public hospitals use natural surveillance, natural access control, territorial concern, and management \& maintenance". The FG meetings were completed during 2014 in a relaxed atmosphere in the middle of the workday. FGs (one each for hospitals A and B) had five participants, and each FG consisted of four participants drawn from engineering department and one participant drawn from quality department. The participants in the FGs were selected based on specified selection criteria, including the number, field, knowledge and experience of staff within engineering and quality department in hospitals A and B; it was believed that each participant would give a particular point of view on CPTED implementation.

Topics, discussion points, and participants' opinions from the FGs were collected and organized into themes, which were then synthesized into an overall summary of feedback. All FGs were conducted by the three researchers. The researchers' roles were to manage the discussion, occasionally guide the conversation to particular areas that were more related to the objective of the study, and they sometimes asked for additional 
clarification regarding the meaning of specific participant comments. Each FG lasted between 120 and 160 minutes.

\section{Study Results}

\subsection{Quantitative Results}

The first aspect of the treatment of the quantitative results is to analyze respondents' demographical data. Table 1 shows that the majority of respondents were male $61 \%$ and most of these workers $65 \%$ were over 30 years old.

Table 1. Demographic information of respondents

\begin{tabular}{llcc}
\hline Demographic Variable & Category & No. & $\%$ \\
\hline \multirow{2}{*}{ Gender } & Male & 199 & 61 \\
& Female & 127 & 39 \\
& 30 years or less & 114 & 35 \\
Age & $31-40$ & 88 & 27 \\
& $41-50$ & 77 & 24 \\
& 51 years and above & 47 & 14 \\
\hline
\end{tabular}

The second aspect of the treatment of the results is to investigate the descriptive statistics regarding the use of CPTED solutions. Descriptive statistics provide a first impression of the studied variables that help interpret the responses of participants, the following criteria were employed. Significant mean values $\geq 3.61$ indicated meaningful usage of architecture solutions. Mean values ranging from 2.31 to 3.60 indicated some usage, and those $\leq 2.30$ indicated low usage of architecture solutions.

Table 3 presents the descriptive statistics regarding natural surveillance. The results demonstrate that the respondents agreed that there is a meaningful usage of visible entries and exits. With respect to the other results-the non-specific use of spaces, sufficient lighting, separate parking areas, main doors that are visible from the driveway, keeping windows free from posters, blind spaces, more than one worker in the site, and the use of convex mirrors-most respondents agreed that the hospitals are engaging in some usage of these techniques.

An analysis of the descriptive statistics regarding natural access control is shown in table 4. The results indicate that there is a meaningful usage of centralized locations for elevators and stairwells, well-identified public areas, well-lit areas, usage of security guards and limitations with respect to access to entrances. The respondents agreed that there is some use of automatic locks, limited roof access, limited usage of one entrance by several departments, some use of ID badges, some use of exterior fences and that unused areas were generally closed.

Table 5 shows that the values of the descriptive statistics for responses related to territorial reinforcement ranged from 3.54 to 3.21 , signifying that some territorial reinforcement was being enacted through the visible positioning of the reception area, usable glass, areas that were easily observed by the public, use of signs, ownership promotion, signage usage and use of property lines.

Table 2. The t-test results for hypothesis (1-4)

\begin{tabular}{llllll}
\hline Hypothesis & Mean & SD & t-calculated & Sig-t & Comment \\
\hline H1: Natural surveillance matters & 3.12 & .79 & 70.97 & .00 & Reject \\
H2: Natural access control matters & 3.60 & .69 & 93.26 & .00 & Reject \\
H3: Territorial concern matters & 3.39 & .78 & 77.88 & .00 & Reject \\
H4: Management \& maintenance matters & 3.27 & .81 & 72.93 & .00 & Reject \\
\hline
\end{tabular}

Table 6 shows that the values of the descriptive statistics for the management $\&$ maintenance matters, and the results indicate that the participants perceived meaningful usage of building repairs, and some adherence to the practices of maintaining clean buildings, maintaining lighting, equipment maintenance, removal of posters and flyers, parking area maintenance and clearly demarcated hours of operation.

The third part of the results involves interpreting the statistics to determine the interest of Jordanian hospitals related to the usage of the components of CPTED; thus, a one-sample t-test was used to address the study 
hypotheses. Table 2 shows the results of the study hypotheses (H1-H4). Table 2 indicates that the Sig-t is 0.00 for all hypotheses. Therefore, we reject the null hypothesis $(\mathrm{H} 1-\mathrm{H} 4)$ and accept the alternative, which suggests that interest levels among Jordanian hospitals related to using the various CPTED components was at some usage level (M: 3.12-3.60), SD: 70.97-93.26).

\subsection{Qualitative Results}

This segment of the study presents and discusses the findings from the two FGs that were implemented after completion of the quantitative study. Data analyzing processes addressed all four components, including natural surveillance, natural access control, territorial concern, and management $\&$ maintenance. The major contributing factors for each dimension appear in Tables 3-6.

The first CPTED dimension to be analyzed is natural surveillance. The majority of the participants from both FGs were not particularly conscious of the importance of natural surveillance in controlling WPV; thus, one respondent said, "I do not think that there is a relationship between hospital design and violence in hospitals". The data revealed that there was an acceptance level of the implementation of natural surveillance components in both hospitals A and B. Table 3 presents the issues related to natural surveillance as implemented in CPTED. The attitudes of respondents in the two FGs were similar. Ten participants indicated that the main entrances were always located where they were visible and that the main street entries and exits were visible and marked: "We are committed to ensuring that the engineering base makes sure that entries and exits should be clearly visible, and paths to reach the exit must be clearly marked". Six participants further pointed to the lack of sites that were unused in hospitals and that, "mostly, we have few areas with nonspecific usage or that are unused. I have noticed that unused spaces were closed". Eight participants stated that there was no policy to separate staff and visitor parking in hospitals: "In all the public hospitals in which I have worked, the parking for doctors, nurses, staff, employees, and visitors were not separated from one another". Ten participants reported that there is little consideration given by hospital management for keeping windows free from posters and other material... "It is common behavior in hospitals that windows are often cluttered and blocked by posters". Another participant said that blocking windows with posters "may improve patient privacy", while another stated, "Many workers believe that the window is a good announcement board". The participants also noted that no one asked for the installation of convex mirrors to detect invisible points. Six participants from the two FGs complained about the absence of specific standards in the design and construction of hospitals.

Table 3. Natural surveillance matters, descriptive statistics and focus group data

\begin{tabular}{lllll}
\hline \multirow{2}{*}{ Natural surveillance matters } & \multicolumn{2}{l}{ Descriptive } & Statistics & \multicolumn{2}{l}{ Focus Group } \\
& Mean & SD & A & B \\
\hline Entry and exit must be clearly visible and marked & 3.62 & 1.04 & $\sqrt{ }$ & $\sqrt{ }$ \\
Avoid non-specific use and non-specific purpose spaces & 3.38 & 1.03 & $\sqrt{ }$ & $\sqrt{ }$ \\
Lighting levels should be sufficient in all used space & 3.55 & 0.93 & $\sqrt{ }$ & $\sqrt{ }$ \\
Visitor parking is separated from staff parking & 3.10 & 1.09 & $\mathrm{X}$ & $\mathrm{X}$ \\
The main door is clearly visible from the driveway & 2.74 & 1.20 & $\sqrt{ }$ & $\sqrt{ }$ \\
Windows should not be blocked with signs or posters & 2.69 & 1.23 & $\mathrm{X}$ & $\mathrm{X}$ \\
Avoid creating blind and hidden spaces & 2.92 & 1.11 & $\sqrt{ }$ & $\sqrt{ }$ \\
Have at least two workers at the same place at all times & 2.96 & 1.07 & $\sqrt{ }$ & $\sqrt{ }$ \\
Use convex mirrors to monitor blind spaces & 3.11 & 1.00 & $\mathrm{X}$ & $\mathrm{X}$ \\
\hline
\end{tabular}

The second CPTED dimension to be analyzed is natural access control. It is clear from the participants' discussion that these matters are implemented at high levels to a certain extent. There was a consensus that each building in each hospital had no more than two entrances and no more than four departments sharing the same entrance. "Hospital A consists of several buildings, and in every building there are between 2 and 4 sections". Another said that, "the design and construction supervision of both hospitals was undertaken by one party". Ten participants agreed that there were no automatic locks for the main entrance, i.e., "typically automatic locks are not used in the hospital", and signs for the public referred to those areas that permitted (or prohibited) the presence of certain people. FGs talked about the signs that point to areas in which the public is allowed in the hospital; it seemed that these signs were used only in the X-ray department: "signs allowing or prohibiting the presence of certain people are used only in the X-ray rooms and not in other places". 
Ten participants stated that all public hospitals in Jordan were protected by an appropriate exterior fence and employed companies to provide security for all aspects of the hospitals. One participant indicated that "security is done by private outsourced companies; often there is non-compliance by these companies with their contracts because these companies rely on elderly people with no training and equipment to assist them with their duties". Another said, "We see that there are security people, but we know that there is no security action". The participants in both FGs gave examples of this path and the examples showed that there was non-compliance with the implementation of security contracts, such as, "there is no problem in what is written in contracts; the problem is in the implementation of contracts". FGs talked about the sites of elevators and stairwells, entranceway lights, and locking unused areas and roofs, and that these were properly implemented. One participant said, "I have worked in five public hospitals, and in all those places, the elevators and stairwells were centrally located, and lighting levels were good." Another reported, "I do not think that there are areas that aren't being used; we are constantly searching for new areas to renovate and use". Several other participants said "that all the areas in use are illuminated, and all roof access points were closed". One reported, "We have backup power generators to ensure hospital lighting in all situations". FGs discussed the issue of ID badges, but it seemed that there was no commitment to using such a system, such as, "there was once a policy under which employees were supposed to wear ID badges, but it resulted in only the doctors who were committed to it".

Table 4. Natural access control, descriptive statistics and focus group data

\begin{tabular}{lllll}
\hline \multirow{2}{*}{ Natural access control } & \multicolumn{2}{l}{ Descriptive } & Statistics & \multicolumn{2}{l}{ Focus Group } \\
& Mean & SD & A & B \\
\hline Limit entrance access to the building to one or two points & 3.61 & 0.89 & $\sqrt{ }$ & $\sqrt{ }$ \\
No more than four departments sharing the same entrance & 3.47 & 1.00 & $\sqrt{ }$ & $\sqrt{ }$ \\
Provide main entrance with automatic locks & 3.54 & 1.07 & $\mathrm{X}$ & $\mathrm{X}$ \\
Protect the buildings with an exterior fence & 3.32 & 1.20 & $\sqrt{ }$ & $\sqrt{ }$ \\
Elevators and stairwells are centrally located and visible & 4.03 & 0.99 & $\sqrt{ }$ & $\sqrt{ }$ \\
Signs showing where the public is and is not allowed & 3.82 & 1.10 & $\mathrm{X}$ & $\mathrm{X}$ \\
Entrances should be well-lit & 3.74 & 1.06 & $\sqrt{ }$ & $\sqrt{ }$ \\
There should be no easy access to the roof & 3.53 & 0.93 & $\sqrt{ }$ & $\sqrt{ }$ \\
Security guards prevent unauthorized access to the building & 3.68 & 1.01 & $\sqrt{ }$ & $\sqrt{ }$ \\
Lock unused areas off from the public & 3.27 & 1.05 & $\sqrt{ }$ & $\sqrt{ }$ \\
Employees must wear ID badges identifying themselves & 3.43 & 1.05 & $\mathrm{X}$ & $\mathrm{X}$ \\
\hline
\end{tabular}

Table 5. Territorial concern matters, descriptive statistics and focus group data

\begin{tabular}{|c|c|c|c|c|}
\hline \multirow{2}{*}{ Territorial concern matters } & \multicolumn{2}{|c|}{$\begin{array}{l}\text { Descriptive } \\
\text { Statistics }\end{array}$} & \multicolumn{2}{|c|}{$\begin{array}{l}\text { Focus } \\
\text { Group }\end{array}$} \\
\hline & Mean & SD & A & B \\
\hline Define the entrances by appropriate signs & 3.38 & 1.00 & $\sqrt{ }$ & $\sqrt{ }$ \\
\hline Define property lines by marked, gates, stations, counters, barriers, etc. & 3.21 & 1.13 & $\sqrt{ }$ & $\sqrt{ }$ \\
\hline $\begin{array}{l}\text { Private and semi-private areas should be easily distinguished from public } \\
\text { areas }\end{array}$ & 3.48 & 0.95 & $\sqrt{ }$ & $\sqrt{ }$ \\
\hline Each unit is provided with an individual entrance to promote ownership & 3.32 & 1.03 & $\sqrt{ }$ & $\sqrt{ }$ \\
\hline The main entrance is easily identifiable and includes plenty of usable glass & 3.52 & 1.09 & $\sqrt{ }$ & $\sqrt{ }$ \\
\hline $\begin{array}{l}\text { Use appropriate signage to clearly identify locations and to direct customers, } \\
\text { guests, residents, etc. }\end{array}$ & 3.31 & 1.11 & $X$ & $X$ \\
\hline $\begin{array}{l}\text { Security and/or reception areas should be positioned to observe all persons } \\
\text { entering the building }\end{array}$ & 3.54 & 1.06 & $\sqrt{ }$ & $\sqrt{ }$ \\
\hline
\end{tabular}

The third CPTED dimension to be analyzed is territorial reinforcement. All participants agreed that there are signs at all entrances and service units. For example, one respondent reported that "there is a sign at the entrance to each site describing whether it is for private or public use". Ten participants from the two FGs agreed that there aren't steering signs or location map in various locations in the hospital: "although these maps are one of 
the requirements for hospital accreditation, they have often not yet been implemented". Most participants agreed that there were differentiations in the exteriors and interiors of private areas compared with public areas. For example, some of the responses of the participants included, for example, "we make private areas distinguishable from public areas by gates or counters", "typically, we separate work areas, such as medical records, the pharmacy, accounting, laboratories, etc.,, by shatterproof glass", and "I think that all work sites are separated from the public by glass or counters". The participants from both FGs agreed that the location of the main entrance made it easy to recognize when approaching the building, and five participants described the main entrance as the following: "The main entrance is located on the main interior street-which insures adequate protection-and is surrounded by shatterproof glass on both sides". To enhance the feeling of legitimate ownership at the entrance of each department, there are visible reception areas that facilitate the reception of workers and visitors.

The fourth CPTED dimension to be analyzed is management \& maintenance. The data analysis of the two FGs supported the proposition that operating schedules are visible to workers but not to the customers: "Hospitals are not posting operating hours for the public; patients who know the operating hours are those who visit the hospital frequently". The participants' comments also confirmed that hospital managers in both hospitals did not prioritize removing outdated posters. As part of a hospital's housekeeping standards, it must have standardized procedures for cleaning activities, including instructions regarding the use of disinfectants. The participants went on to voice their strong opinion that hospital managers do not pay attention to some details. In relation to hospital cleaning services, participants stated that "cleaning is done by outsourced companies, and choosing these companies is centrally undertaken; the contracts with these companies are entered into on the basis of global standards. These contracts are not implemented in accordance with the written contracts. There is no coordination between the people who write these contracts and choose the companies to execute them, on one hand, and the workers and supervisors in hospitals who implement them, on the other. Thus, there is no coordination or even meetings regarding what we must do and what we would like to require in the contracts".

In relation to inspections of the physical facility, hospitals must have an overall plan and implement programs to manage maintenance activities. The main issue that emerged from the two FGs is that maintenance is highly regarded by many other services in the hospitals, such as the following: "The hospital has a maintenance department, and all maintenance requests are implemented correctly" and "There is no plan and no implemented program for continuously inspecting and maintaining the physical facility". The participants reported that there are not any problems with maintenance of wall paint, but there is little consideration given by the hospital management for the parking areas: "There is a low priority for parking, and no schedule for inspection and preventive maintenance according to a set of standards". The participants in FGs noted the lack of cleanliness, lighting and safety in the parking lots.

Table 6. Management \& maintenance matters, descriptive statistics and focus group data

\begin{tabular}{|c|c|c|c|c|}
\hline \multirow[t]{2}{*}{ Management \& maintenance matters } & \multicolumn{2}{|c|}{$\begin{array}{l}\text { Descriptive } \\
\text { Statistics }\end{array}$} & \multicolumn{2}{|c|}{$\begin{array}{l}\text { Focus } \\
\text { Group }\end{array}$} \\
\hline & Mean & SD & A & $\mathrm{B}$ \\
\hline Operating hours should be clearly displayed & 2.60 & 1.24 & $\sqrt{ }$ & $\sqrt{ }$ \\
\hline Faded or outdated posters and broken signs should be removed & 3.32 & 1.09 & $\mathrm{X}$ & $\mathrm{X}$ \\
\hline Keep the building clean. & 3.58 & 1.11 & $\sqrt{ }$ & $\sqrt{ }$ \\
\hline $\begin{array}{l}\text { Inspect property, lighting, equipment and facilities to ensure satisfactory } \\
\text { operation. }\end{array}$ & 3.41 & 1.13 & $\sqrt{ }$ & $\sqrt{ }$ \\
\hline Keep the building and walkways repaired and painted & 3.66 & 1.00 & $\sqrt{ }$ & $\sqrt{ }$ \\
\hline Maintain lighting, and consider timers, sensors, and the use of long-life lamps & 3.38 & 1.04 & $\sqrt{ }$ & $\sqrt{ }$ \\
\hline $\begin{array}{l}\text { Maintain parking areas to high standards of, cleanliness and keep them light } \\
\text { in color to reflect light easily }\end{array}$ & 2.97 & 1.10 & $X$ & $\mathrm{X}$ \\
\hline
\end{tabular}

\section{Conclusion}

The purpose of this study was to improve our awareness regarding the use of architectural and management solutions to control WPV in Jordanian hospitals by exploring the following study question: How do Jordanian public hospitals use the various CPTED components to prevent WPV? The study issues were identified to 
address the following study hypothesis: Jordanian hospitals do not use the CPTED components of natural surveillance, natural access control, territorial reinforcement, or management \& maintenance. This study is consistent with previous studies that agree that implementing the various components of the CPTED approach can reduce crime and WPV (Travis, 1996; Katyal, 2002; Parnaby, 2006; Cozens, Saville, \& Hillier, 2005).

To our knowledge, ours is the first study to discuss the usage of CPTED components in a hospital to control WPV. The results gathered from our participants reveal a limited view toward the usage of CPTED components in both hospitals; this outcome reflects a similarity in both design and in management methods in Jordanian public hospitals. These hospitals were built or rebuilt during the last ten years and were managed by a group of managers whose employment moves among the public hospitals in Jordan.

This study's findings demonstrate the lack of knowledge among workers regarding the role of design effects in controlling WPV and consistently indicated that they were not trained in CPTED principles; therefore, these respondents did not generally understand what the CPTED components sought to provide, what the design offers, and/or how to exploit the design of a hospital that enables CPTED principles.

There is also a lack of cooperation and communication among those who design and those who manage and operate hospitals. There is no organizing management data or strategic direction that specifically addresses WPV, which is a basic problem in Jordanian hospitals. This result will frustrate and perhaps even anger healthcare providers, particularly when they conclude that the WPV problem will not be solved in the near term.

In general, the results indicate some usage of the various CPTED dimensions, including natural surveillance, natural access control, territorial reinforcement, and management $\&$ maintenance. The results also showed that the best uses of CPTED principles are found with respect to the location of main entrances to elevators, stairwells and for each department. Conversely, the findings also show that the CPTED components that were least adhered to were those related to parking, use of convex mirrors, wearing ID badges, the use of directional signals, keeping windows clear of posters and clutter and clear communication regarding the operating hours and services provided by each hospital.

Workers are not convinced that the actions of outsourced companies comply with the underlying contracts that should govern these activities. There seems to be a perception that contracts are written using scientific and international standards but are implemented in a manner that falls short of the contractual requirements.

Perhaps because hospital design indirectly affects WPV in hospitals, Jordanian public hospitals have used some components of CPTED, but Jordanian public hospitals are still considered violent workplaces because hospital design has not had a significant effect on hospital WPV, which indicates that there are other factors causing violence in such hospitals. In fact, the present study suggests that there may be other important drivers of WPV in hospitals. The encouraging implication of this finding is that it gives hospital leaders a path to follow to meet the challenge of preventing WPV and to improve these hospitals' working environments.

This study has four major implications for future research. First, this study focused on major referral hospitals, whereas future studies might focus on all public hospitals in Jordan. Second, this study focused on public hospitals, whereas future research might investigate the successful experiences of private hospitals in Jordan. Third, this study has undertaken to study the role of CPTED components on WPV, whereas future studies can expand the role of different environmental factors on WPV. Fourth, future studies can address WPV in non-healthcare institutions.

Those with the responsibility for establishing and operating Jordanian hospitals stand to gain the most from this study because it will provide them with a better and clearer understanding of how to address WPV. Adopting scientific theories and trends will improve the environment and the working conditions of hospitals. Specific standards to prevent WPV must be developed, published and adhered to with a professionalism that accompanies established hospitals. Hospitals must help educate and train workers hospital workers to learn how to exploit the advantages that are inherent in the CPTED design to take advantage of the features of the CPTED approach. When managers take adequate time to understand the successful experiences of others in addressing deficiencies, setting strategic targets can make a difference in the workplace.

\section{References}

Al-Nsour, M., \& Khawaja, M. (2009). Domestic Violence against Women in Jordan: Evidence from Health Clinics. J Fam, 24, 569-575.

Bowie, V., Fisher, B., \& Cooper, C. (2012). Workplace Violence, Issues, trends, strategies. UK: Willan Publishing. 
British Columbia Housing Matters. (2014). Crime Prevention through Environmental Design. Retrieved June 21, 2014, from http://www.bchousing.org/Partners/Standards_Procurement/Standards

Charney, W. (2010). Handbook of Modern Hospital Safety (2nd ed.). USA: Taylor \& Francis Group.

Cottrell, R., \& McKenzie, J. (2011). Health Promotion \& Education Research Methods: Using the Five Chapter Thesis/Dissertation Model (2nd ed.). Canada: Jones and Bartlett Publishers.

Cozens, P., Saville, G., \& Hillier, D. (2005). Crime Prevention through Environmental Design (CPTED): A Review and Modern Bibliography. Property Management, 23(5), 328-356. http://dx.doi.org/10.1108/0263 7470510631483

Crowe, T., \& Zahm, D. (1994). Crime Prevention through Environmental Design. USA: Center for Problem Oriented Policing.

Cullen, F., \& Wilcox, P. (2010). Encyclopedia of Criminological Theory (Vol. 1). California: Sage Publications.

Doll, L., Bonzo, S., Mercy, J., \& Sleet, D. (2007). Handbook of Injury and Violence Prevention. Atlanta: Springer. http://dx.doi.org/10.1007/b136518

Duarte, O., Lulham, R., \& Kaldor, L. (2011). Co-designing out crime. Co-Design, 7(3), 155-168. http://dx.doi. org/10.1080/15710882.2011.630476

Duffy, V. (2013). Advances in Human Aspects of Healthcare. New York: Taylor \& Francis Group.

Elizabeth, C., \& Jonathan, D. (2013). Quantitative Health Research: Issues And Methods: Issues and Methods. England: Mc Graw-Hill.

Elliott, P. (1997). Violence in Heaitii Care, What Nurse Managers Need to Know. Nursing Management, 28(12), 38-41.

Federal Emergency Management Agency. (2008). Site and Urban Design for Security: Guidance Against Potential Terrorist Attacks. USA: Federal Emergency Management Agency.

Fennelly, L. (2012). Handbook of Loss Prevention and Crime Prevention. USA: Elsevier.

Fennelly, L., \& Crowe, T. (2013). Crime Prevention Through Environmental Design (3rd ed.). USA: Elsevier.

Gagne, M. (2014). The Oxford Handbook of Work Engagement, Motivation, and Self-Determination Theory. Oxford University Press. http://dx.doi.org/10.1093/oxfordhb/9780199794911.001.0001

Hacioglu, U., \& Dinçer, H. (2014). Globalization and Governance in the International Political Economy. USA: Information Science Reference. http://dx.doi.org/10.4018/978-1-4666-4639-1

Hall, D., \& Giglio, N. (2010). Architectural Graphic Standards for Residential Construction. Canada: John Wiley \& Sons.

Hamby, S., \& Grych, J. (2012). The Web of Violence: Exploring Connections Among Different Forms of Interpersonal Violence and Abuse. USA: Springer.

Holmes, D., Perron, A., \& Rudge, T. (2013). (Re)Thinking Violence in Health Care Settings: A Critical Approach. England: Ashgate.

Hopper, L. (2013). Landscape Architectural Graphic Standards. New Jersey: Wiley \& Sons.

Humphrey, C., \& Lee, B. (2008). The Real Life Guide to Accounting Research: A Behind the Scenes View of Using Qualitative Research Methods. England: Elsevier.

Immy, H. (2005). Qualitative Research In Health Care. England: Mc Graw-Hill House.

International Labour Office. (2003). Moral Harassment-Work Organization to Blame? Geneva.

Jordanian Minister of Health. (2014). Assault on Medical Staff. Amman: Ministry of Health.

Katyal, N. (2002). Architecture as Crime Control. The Yale Law Journal, 12, 1039-1139. http://dx.doi.org/10.23 $07 / 797618$

Kelloway, K., \& Cooper, C. (2011). Occupational Health and Safety for Small and Medium Sized Enterprises. UK: Edward Elgar. http://dx.doi.org/10.4337/9780857938701

Kelly, P., \& Portes, A. (2013). Health Care and Immigration: Understanding the Connections. Canada: Routledge.

Kerr, K. (2010). Workplace Violence: Planning for Prevention and Response. UK: Elsevier. 
Lyneham, J. (2000). Violence in New South Wales Emergency Departments. Australian Journal of Advanced Nursing, 18(2), 8-17.

Mayhew, C., \& Chappell, D. (2003). Workplace Violence in the Health Sector, A Case Study in Australia. Journal of Occupational Health and Safety, 19(6), 1-45.

Ministry of Health. (2013). Annual Statistical Book. Amman: Directorate of Information \& Research.

Newman, C., Vries, D., Kanakuze, J., \& Ngendahimana, G. (2011). Workplace Violence and Gender Discrimination in Rwanda's Health Workforce: Increasing Safety and Gender Equality. Newman et al. Human Resources for Health, 9(19), 1-13.

Newman, O. (1972). Defensible Space: People and design in the violent city. London: Architectural Press Ltd.

Nicholas, J. (2012). Crime Prevention Through Environmental Design Strategies. Oshkosh: Oshkosh Police Department.

Paludi, M., Nydegger, R., \& Paludi, C. (2006). Understanding Workplace Violence: A Guide for Managers and Employees. London: Praeger Publishers.

Parnaby, P. (2006). Crime Prevention through Environmental Design: Discourses of Risk, Social Control, and a Neo-liberal Context. Canadian Journal of Criminology and Criminal Justice, 1-29. http://dx.doi.org/10.31 $38 /$ cjecj.48.1.1

Patrick, W. (2013). The Call of Nursing: Stories from the Front Lines of Health Care. New York: Hudson Whitman.

Philpott, D., \& Grimme, D. (2009). The Workplace Violence Prevention Handbook. USA: Government Institutes.

Pyrek, K. (2011). Healthcare Crime: Investigating Abuse, Fraud, and Homicide by Caregivers. New York: Taylor \& Francis Group. http://dx.doi.org/10.1201/b10522

Queensland Crim Prevention Programs. (2007). Crime Prevention through Environmental Design. Australia: Queensland Government.

Reed, J., \& Payton, V. (1997). Focus Groups: Issues of Analysis and Interpretation. Journal of Advanced Nursing, 26, 765-771. http://dx.doi.org/10.1046/j.1365-2648.1997.00395.x

Saif, N., \& Saleh, A. (2013). Managers' Concern Regarding Employee Empowerment in Jordanian Public Hospitals. Interdisciplinary Journal of Contemporary Research in Business, 5(3), 78-86.

Saleh, A., \& Saif, N. (2014). Workplace Violence and Hospital Initiative. European Journal of Social Sciences, 44(3), 230-247.

Saville, G., \& Cleveland, G. (2008). Second-Generation CPTED: The Rise and. Boca Raton: Taylor \& Francis Group.

Schneider, R., \& Kitchen, T. (2007). Crime Prevention and the Built. London: Routledge.

Sennewald, C., \& Christman, J. (2008). Retail Crime, Security, and Loss Prevention: An Encyclopedic Reference. USA: Elsevier.

Silverstein, C. (2011). The Initial Psychotherapy Interview: A Gay Man Seeks Treatment. USA: Elsevier.

Taylor, J., \& Rew, L. (2010). A Systematic Review of the Literature: Workplace Violence in the Emergency Department. Journal of Clinical Nursing, 20, 1072-1085. http://dx.doi.org/10.1111/j.1365-2702.2010. 03342.x

The Japan Institute for Labour Policy and Training. (2013). Workplace Bullying and Harassment. JILPT.

Tipton, H., \& Krause, M. (2007). Information Security Management Handbook (6th ed.). USA: Taylor \& Francis Group. http://dx.doi.org/10.1201/9781439833032

Travis, J. (1996). Crime Prevention Through Environmental Crime Prevention Through Environmental. National Institute of Justice. Washington, D.C.: U.S. Department of Justice.

U.S. Department of Justice. (1996). Combating Violence and Delinquency: The National Juvenile Justice Action Plan. USA: Office of Justice Programs.

U.S. Safety and Justice Program. (2009). Neighborhood Effects on Crime and Youth Violence: The Role of Business Improvement Districts in Los Angeles. Santa Monica: RAND Corporation.

Vellani, K. (2007). Strategic Security Management: A Risk Assessment Guide for Decision Makers. USA: 
Elsevier.

Walsh, J. (2003). Asset Protection and Security Management Handbook. USA: POA Publishing.

Wassell, J. (2009). Workplace Violence Intervention Effectiveness: A Systematic Literature Review. Effective Intervention Review, 1-4.

Wiid, J., \& Diggines, C. (2009). Marketing Research. Cap Town: Juta and Company.

World Health Organization. (2002). Guidelines for Addressing Workplace Violence in the Health Sector. Geneva: International Labour Office.

Wortley, R., \& Mazerolle, L. (2011). Environmental Criminology and Crime Analysis. New York: Routledge.

Zahm, D. (2007). Using Crime Prevention Through Environmental Design in Problem-Solving. USA: U.S. Department of Justice.

Zun, L. (2013). Behavioral Emergencies for the Emergency Physician. New York: Cambridge University Press. http://dx.doi.org/10.1017/CBO9781139088077

\section{Copyrights}

Copyright for this article is retained by the author(s), with first publication rights granted to the journal.

This is an open-access article distributed under the terms and conditions of the Creative Commons Attribution license (http://creativecommons.org/licenses/by/3.0/). 